\title{
Honorary and ghost authorship in high impact biomedical journals: a cross sectional survey
}

The authors of this article, Joseph S Wislar and colleagues, have advised us of two errors in their article (BMJ 2011;343:d6128, doi:10.1136/bmj.d6128). Firstly, the "data sharing" statement at the end of their article is wrong. It said that "de-identified raw dataset and accompanying analytical files" were available, whereas in fact it should read: "We did not obtain permission to share data from the survey participants; thus, no additional data are available." (The authors told us that when they first conducted their survey in 2009, they did not contemplate the potential for data sharing and so did not prospectively seek the necessary permissions.) Secondly, in the "web extra table 5" (in the Data Supplement) the percentage of ghost authors present when a corresponding author reported that an unnamed individual participated in writing the article should be $0.16 \%$, not $0.3 \%$. The authors have stated that this error does not affect any other data in the web extra content or in the main article.

Cite this as: BMJ 2011;343:d7677

๑ BMJ Publishing Group Ltd 2011 